Nigerian Journal of Physiological Sciences 22 (1-2): 55-58 @Physiological Society of Nigeria, 2007

Available online/abstracted at http://www.biolineinternational.org.br/njps; www.ajol.info/journals.njps; www.cas.org

\title{
OCULAR EFFECTS OF CHRONIC EXPOSURE TO WELDING LIGHT ON CALABAR WELDERS
}

\author{
K. G. DAVIES ${ }^{1}$; U. ASANA ${ }^{2}$; C. O. NKU ${ }^{3}$ and E. E. OSIM ${ }^{3}$ \\ ${ }^{1}$ Department of physiology, Faculty of Basic Medical Sciences, University of Uyo, Uyo, Nigeria \\ Departments of Ophthalmology $y^{2}$ and Physiology, college of Medical Sciences, University of Calabar, Calabar, \\ NigeriaE-mail: emeosim@yahoo.com
}

Summary: It was generally observed that welders in Calabar, Nigeria did not always wear their protective goggles during welding. Since chronic exposure to welding light can impair vision this study was done to assess the effect of exposure to welding light on ocular function of welders in Calabar, Nigeria. There were 195 subjects comprising 110 welders (test) and 85 control subjects. Both groups were all male and had similar age range. The tests employed were clinical examination for ocular disorders, assessment of visual acuity, and opthalmoscopy. Test questionnaire was also used to record information on length of service, precautionary measures at work place, age and past ocular illnesses. The study also compared incidence of ocular disorders between the two groups of welders (arc and carbide welders). The mean ages of the welders and their control were not significantly different $(27.53 \pm 10.0$ vs $27.78 \pm 8.5$ yrs respectively). There was a significantly $(\mathrm{P}<0.01)$ higher incidence of pingueculum, cataract, allergic conjunctivitis, corneal opacity, and keratoconjunctivitis (arc eye) in welders than in their control subjects. However, visual acuity, incidence of pterygium and glaucoma were similar. Between the two groups of welders, the incidence of pterygium, corneal opacity and keratoconjunctivitis was significantly $(\mathrm{P}<0.01)$ higher in arc welders than carbide welders. The incidence of pingueculum and glaucoma were however, similar. In conclusion, chronic exposure to welding light without adequate precaution may cause ocular disorders. Arc welding is more dangerous to ocular function than carbide welding. Length of service and age are predisposing factors to ocular disorders in the welding business.

Key Words: Keratoconjunctivitis, incidence, cataract, pterygium.

\section{Introduction}

Welding emits a wide spectrum of radiations ranging between $200 \mathrm{~nm}$ - 1400nm. These radiations include ultraviolet (UV) rays (200400nm). Visible light (400-700nm) and infrared rays $(700-1400 \mathrm{~nm})$. Ultraviolet radiation and far infra-red (IR) are absorbed by the cornea and lens whereas visible light and near infra-red penetrate to the retina (Fich et al, 1993; Voke, 1999).

Unprotected exposure of the eyes to these rays is known to cause both acute and chronic ocular disorders. Acute exposure to UV radiation for instance, causes photokeratitis (commonly called, welder's flash eye or arc eye). This condition, known for more than a century now, is associated with arc welders who strike the arc before lowering their protective helmet. (Voke, 1999). It is characterized by foreign body sensation (grittiness), photophobia, tearing, blepharospasm and pain. Phtotokeratitis is usually seen a few hours following exposure and typically resolved within 72 hours. It does not have long-term squelae (Voke, 1999; Magnavita, 2002). Chronic UV radiation exposure on the other hand is associated with a high prevalence and incidence of long term changes in the outer part of the eye in welders (Narda et al, 1990; Norm et al, 1991).
Radiation in the visible and near - IR spectrum (400-1400nm) penetrates the eye to be absorbed by the retina and may cause thermal or photochemical damage. Retinal damage induced by arc welding is referred to as phototoxic maculopathy. In most cases, retinal injuries heal spontaneously without loss of vision (Magnavita, 2002). However, severe burns of the macula may lead to permanent, complete or partial loss of central vision.

The prevalence and seriousness of eye disorders depend on both the intensity and characteristics of emitted radiation and the availability of protective measure. Studies performed on Europeans showed that degenerative changes in the macula were very frequent among East European welders, who did not often adhere to protective measures. On the other hand, retinal lesions were infrequent among Western Europeans who, usually adopted protective measure (Gos et al, 1984).

However, such studies have not been done in Nigeria which is generally characterized with poor compliance to eye safety rules (Okoye 2002). Therefore, this study aimed at determining the visual acuity and prevalence of ocular disorders among welders and compared with a control 
population. The incidence of ocular diseases between two groups of welders (arc and carbide welders) was also compared.

\section{Materials and Methods}

Subjects were randomly selected from Calabar municipality, Cross River State, Nigeria. Test subjects were welders operating along the major streets of Calabar municipality who gave their consent. The control group comprised apparently healthy males of similar age as the test group who were not welders. Tests conducted were clinical examination for ocular disorders namely: pterygium, pingueculum, conjunctivitis, photokeratitis, corneal scars and cataract. Other procedures were visual acuity assessment (using Snellen's chart), direct ophthalmoscopy and slit lamp ophthalmoscopy. Test questionnaires were used to record information on length of service, precautionary measures at work place, age and past ocular illnesses.

A total of 195 subjects, comprising 110 welders and 85 control subjects were employed in this study. The welders were of 2 categories namely; arc welders $(n=90)$ and carbide welders $(n=20)$.

\section{Statistical Analysis}

The student t-test was used to determine the significant difference between mean values in the test and control groups. P-values less than 0.05 were taken as significant. The chi square test was used to test for significance between two percentages. $\mathrm{P}$ values less than 0.05 was considered as statistical significant.

\section{Results}

The mean ages of the welder and their control were not significantly different $(27.53 \pm 10.0$ vs $27.78 \pm 8.5$ yrs respectively). The mean duration of exposures of the welders to welding light was $8 \mathrm{yrs}$ \pm 8.5 , Visual acuity was not significantly different between the welders and their control $(0.988 \pm 0.04$ vs $1.01 \pm 0.04)$.

\section{Ocular disorders amongst all the welders and their} control

The following disorders were significantly higher in welders than in control: keratoconjuncttivitis, pingueculum, cataract, allergic conjunctivitis and corneal opacity. However, the incidence of peterygium and glaucoma subjects was similar in both groups. (Table 1)

Ocular disorders amongst Arc welders only and their control

The incidence of all the ocular disorders studied except glaucoma was higher in arc welders than their control (Table 2).

Ocular disorders amongst carbide welders only and their control

The incidence of pingueculum and allergic conjunctivitis was significantly higher in carbide welders than in their control. However, the incidence of pterygium, cataract, corneal opacity and glaucoma subject was similar in both groups (Table 3).

Table I: Comparison of Ocular Disorders between Control and Test Groups

\begin{tabular}{llll}
\hline Ocular Disorders & $\begin{array}{l}\text { Welders } \\
(\%)\end{array}$ & $\begin{array}{l}\text { Controls } \\
(\%)\end{array}$ & Significance \\
\hline Pterygium & 18 & 14 & N.S \\
keratoconjuctivitis & 80 & 0 & $* * *$ \\
Pingueculum & 19 & 7 & $*$ \\
Cataract & 2.5 & 0 & $* *$ \\
Allergic Conjunctivitis & 20 & 7.7 & $* *$ \\
Corneal Opacity & 5.8 & 0 & $* *$ \\
Glaucoma & 13.89 & 11.5 & N.S \\
$*=p<0.05 ; * *=P<0.01 ; * * *=P<0.001 ;$ & NS $=$ Not statistically significant
\end{tabular}

Table 2: Comparison of Incidence of Ocular Disorder between Arc Welders and Control subjects.

\begin{tabular}{llll}
\hline Ocular Disorders & Welders $(\%)$ & Controls $(\%)$ & Significance \\
\hline Pterygium & 21 & 14 & $*$ \\
Pingueculum & 18 & 7 & $* *$ \\
Cataract & 2.2 & 0 & $* *$ \\
Allergic & 20 & 7.7 & $* *$ \\
Conjunctivitis & & & $* *$ \\
Corneal Opacity & 7 & 0 & N.S \\
Glaucoma Suspect & 10 & 10 & \\
\hline
\end{tabular}

\footnotetext{
$*=P<0.05 ; * *=P<0.01 ; N S=$ Not statistically significant.
} 
Welding light exposure on welders

Table 3: Comparison of Incidence of Ocular Disorders between Carbide Welders and Control Subjects

\begin{tabular}{llll}
\hline Ocular Disorders & $\begin{array}{l}\text { Welders } \\
(\%)\end{array}$ & $\begin{array}{l}\text { Controls } \\
(\%)\end{array}$ & Significance \\
\hline Pterygium & 11.8 & 14 & N.S \\
Pingueculum & 20 & 7 & $*$ \\
Cataract & 0 & 0 & N.S \\
Allergic Conjunctivitis & 20 & 7.7 & $* *$ \\
Corneal Opacity & 0 & 0 & N.S \\
Glaucoma & 12 & 11.5 & N.S \\
Keratoconjunctivitis & 0 & 0 & N.S \\
\hline
\end{tabular}

Table 4: Comparison of Incidence of Ocular Disorders between Arc and Carbide Welders

\begin{tabular}{llll}
\hline Disorders & $\begin{array}{l}\text { Arc Welders } \\
(\%)\end{array}$ & $\begin{array}{l}\text { Carbide } \\
\text { Welders } \\
(\%)\end{array}$ & Significance \\
\hline Pterygium & 21 & 11.0 & $*$ \\
Pingueculum & 18 & 20 & N.S \\
Cataract & 2.2 & 0 & $* *$ \\
Allergic Conjunctivitis & 20 & 20 & N.S \\
Corneal Opacity & 7.7 & 0 & $* *$ \\
Glaucoma & 12 & 10 & N.S \\
Keratoconjunctivitis & 100 & 0 & $* * *$ \\
\hline NS $=$ not significant vs control $; *=P<0.05$ vs control; $* *=P<0.01$ vs control, $* * *=P<0.001$ vs control
\end{tabular}

Ocular disorders amongst arc welders and Carbide welders

The incidence of keratoconjunctivitis, cataract, pterygium and corneal opacity was higher in arc welders than in Carbide welders. Incidence of pingueculum, allergic conjunctivitis and glaucoma was similar between the two sub-groups of welders. (Table 4).

\section{Discussion}

This study has shown that chronic exposure to welding light without adequate precautionary measures caused ocular orders. There was a higher incidence of pingueculum, cataract, keratoconjunctivitis, corneal scars and allergic conjunctivitis $(\mathrm{P}<0.01)$ among welders than in control subjects. The incidence of pterygium and glaucoma was however similar between test and control subjects. Except for pterygium whose incidence was not different between welders and their control, the findings in this study are in agreement with the results of other investigators who showed that the incidence of pterygium, cataract, pingueculum, corneal scars and keratoconjunctivitis (arc eye) was higher in welders than in control subjects (Voke, 1999). The contrast in the incidence of pterygium between this study and that reported by other workers may be due to the fact that in this study, welders comprised carbide and arc welders unlike in other studies mentioned above that used only arc welders. It is well established that carbide welding generally presents little hazard to the eyes since ultraviolet emission is quite small and the brightness of the flame is not much more than candle flame (Sliney et al, 1980). This fact has also been demonstrated by this study. Comparison of the incidence of ocular disorders between carbide welders and control were similar for all ocular disorders examined for except for pingueculum and allergic conjunctivitis which were higher in the carbide welders. It may also be due to ethnic differences since this is the first study of this kind using blacks.

On the other hand, comparison of incidences of the disorders between arc welders and control showed that all the disorders examined for except glaucoma subjects were higher in arc welders. As already stated, this study also found higher incidence of allergic conjunctivitis among welders. This finding has not been reported in literature. It is possible therefore, that the investigators did not look for it. There may also be a racial difference, since this is the only study that used blacks in the tropics as subjects.

It is likely that the causative factor for the increased ocular disorders is chronic exposure to welding light. However, it is conceivable that other confounding causative factors maybe responsible. Various gases are emitted during welding and can cause ocular disorders. This may likely be the reason carbide welders who (unlike arc welders) were not exposed to any hazardous light source also had higher incidence of pingueculum when compared with the control. It is also very likely that the higher incidence of allergic conjunctivitis was due to metal smoke emitted during welding. Unfortunately it was not possible to measure the gases emitted or quantify the 
amount of light that entered the eyes of the test subjects owing to technical reasons. The above speculations are in agreement with report by AFSCME, (2004) which state that welding smoke can affect any part of the body.

The higher incidence of corneal scar amongst the welders, though not related to welding light may be another cause of ocular disorders. Corneal scar is usually caused by iron filling or other foreign body penetration. Unfortunately these workers were not informed of these hazards during their training or apprentice.

In conclusion, chronic exposure to welding light without adequate precautionary measures may cause ocular disorders including allergic conjunctivitis not previously reported. Arc welding is more dangerous to ocular function than carbide welding.

\section{Acknowledgement}

We acknowledge the staff members of the Department of Ophthalmology, UCTH, Calabar. Of particular note are Drs. Ibanga, Inyang, Eduvie, Chukwu and Etim who carried ocular examination in the hospital and fundoscopy.

\section{References}

American Federation State Country Municipal Employee Health and Fact Sheet "welding Hazards" 2004.
Britain, G. P. (1988). Retinal burns caused by exposure to MIG-welding arcs: report of two cases. Br J Ophthalmol. 72: 570-575.

Fich, M., Dahl, H., Fledelius, H. (1993). Maculopathy caused by welding arcs. A report of 3 cases. Acta Ophthalmol Copenh; 71: 403404.

Gos, R., Stephien, J., Horowski, P. (1984). State of the eyes in welders of Division M-5, Brown Coal Mine in Belchatow. Med Pre; 35: 133136.

Magnavita, N. (2002). Photoretinitis: an underestimated occupational injury? ccupational Medicine. 52: 2233-225.

Narda, R., Magnavita, N., Sacco, A. (1990). Affezioni oculars nei saldatori: uno studio longitudinale. Med. Lav. 81: 399-409.

Norm, M., Frank, C., (1991). Long-term changes in the outer part of the eye in welders.

Prevalence of spheroid degeneration, pinguecula, pterygium, and corneal cicatrices. Acta Ophthalmol Copenh 69: 382-386.

Okoye, O. I., Umeh, E. (2002). Eye health of Industrial workers in Southeastern Nigeria. West African Journal of Med. 21 (2): 132-137.

Sliney, D. H., Wolbarsht, M. L. (1980). Safety with layers and other optical sources. New York. P1 Press. P. 1-5.

Voke, J. (1999). Radiation effect on the eye - cular effect of ultraviolet radiation. Optometry Today. 8:30-35. 